\title{
Dietary selenized yeast and CLA isomer mixture affect fatty- and amino acid concentrations in the femoral muscles and liver of rats
}

\author{
M. Czauderna ${ }^{1,3}$, J. Kowalczyk ${ }^{1}$, K.M. Niedźwiedzka ${ }^{1}$, L. Leng ${ }^{2}$ \\ and K. Cobanova ${ }^{2}$
}

\author{
${ }^{1}$ The Kielanowski Institute of Animal Physiology and Nutrition, Polish Academy of Sciences \\ 05-110 Jabtonna, Poland \\ ${ }_{2}^{2}$ Institute of Animal Physiology, Slovak Academy of Sciences \\ 04001 Košice, Slovak Republic
}

(Received 27 October 2008; revised version 13 February 2009; accepted 20 March 2009)

\begin{abstract}
The effect of diets enriched in CLA isomer mixture (CLAmix) and/or selenized yeast (Se-Y) on the concentration of fatty acids (FA), amino acids (AA), Se, Fe and $\mathrm{Zn}$ in the liver and femoral muscles was studied on 4 groups of 7-8 rats aged 8 weeks. Rats were fed the Labofeed $\mathrm{H}$ diet for 29 days (control group) or the diet enriched with 2\% CLAmix with or without $1.2 \mathrm{ppm} \mathrm{Se}$ as Se-Y (the experimental groups). Feeding the CLAmix-enriched diet reduced the body weight of rats, while the diet containing CLAmix and Se-Y increased it in comparison with the control rats. The muscle concentrations of non-essential and essential amino acids, and in particular, sulphur amino acids $(\Sigma \mathrm{S}-\mathrm{AA})$ can be significantly increased, while the muscle concentration of total fatty acids ( $\Sigma$ FA), decreased by feeding the diet with Se-Y and CLAmix. Feeding the diet with Se-Y leads to significant lowering of the ratios of $\Sigma$ S-AA, methionine, cysteine and taurine to $\mathrm{Se}$ concentrations in the liver and muscles as compared with the control group. Dietary Se-Y or CLAmix lead to a decrease in the concentrations of atherogenic and thrombogenic saturated fatty acids (SFA) in muscles. Feeding the diet with Se-Y and CLAmix increased the concentration of Se and the atherogenic and thrombogenic indexes in the liver and muscles. There were also higher concentrations of cis 9trans 11CLA and t10c12CLA in the muscles compared with the concentrations of these isomers in the liver of rats fed the diets enriched in only CLAmix. Deposition in the liver and femoral muscle of trans10cis12CLA was higher in both tissues than cis9trans11CLA. The diet with CLAmix, regardless of the presence of Se-Y, decreased the rate of elongation and $\Delta 5$-, $\Delta 9$-desaturase capacities of in the liver and muscle. The diet with CLAmix effectively increased the ratio of PUFAn-3/SFA,
\end{abstract}

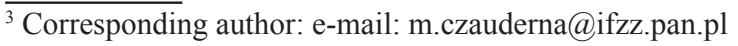




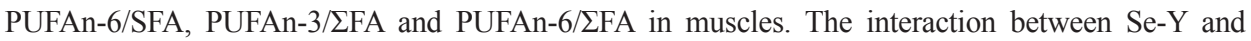
CLAmix decreased the capacity of liver and muscle desaturation, i.e. these dietary additives reduced the ratio of unsaturated fatty acids to SFA in the liver and muscles.

KEY WORDS: selenized yeast, fatty acids, amino acids, CLA isomers, Se, liver, femoral muscles, rats

\section{INTRODUCTION}

The trace element selenium (Se) is a component of over 25 Se-enzymes (e.g., Se-protein $\mathrm{P}$ or thioredoxin reductase, isozymes of the glutathione-peroxidase (GPx) family: GPx-1, -2, -3, -4 and -6) involved in diverse metabolic processes (Schomburg et al., 2004). Therefore, Se has recently come to be considered an essential element in animal and human diets, and organic or inorganic forms of Se are commonly used as dietary additives for the treatment of Se deficiency (Surai, 2006; Boosalis, 2008). As the molecular physiology of Se-proteins/Seenzymes became known, it became apparent that Se concentrations differentially influenced Se-protein expression in animals and humans (Raymond and Kristina, 2005). Nearly half of Se-proteins have been implicated in antioxidant functions, and Se-cysteine (Se-Cys) is essential in the active center of Se-proteins that carry out redox reactions (Tapiero et al., 2003; Suzuki, 2005). Indeed, these proteins act in synergy with tocopherols and provide a second line of defense against hydroperoxides, which can damage membranes and other cell structures (Tapiero et al., 2003). There are numerous studies showing that an adequate Se level in animal and human diets protects against peroxidation of unsaturated fatty acids (FA) and accumulation of carbonyl moieties on proteins produced by oxidative stress (Tapiero et al., 2003). Feeding rats dietary selenized yeast (Se-Y; 83\% Se as Se-Met) (Rayman, 2004; Weiss and Hogan, 2005) results in induction of GPx activity, indicating that in these animals, part of the Se added to the diet is converted to Se-Cys, which is an essential chemical form of Se for the synthesis of Se-proteins possessing antioxidant properties (Whanger, 2004). Moreover, the principal physiological roles of half of Se-proteins are to maintain the appropriate metabolism of arachidonic acid and low concentrations of pre-oxides or free radicals within cells, thus decreasing oxidative stress in living organisms (Tapiero et al., 2003; Schweizer et al., 2005). GPx acts in synergy with tocopherol in the regulation of lipid peroxidation. Recent studies documented that phospholipid hydroperoxide GPx in particular, interacted more directly than cytosolic and mitochondrial GPx in protecting PUFA from peroxidation damage (Crespo et al., 1995; Tapiero et al., 2003). Moreover, a positive correlation was observed between concentrations of unsaturated FA and the dietary content of Se (Crespo et al., 1995; Tanguy et al., 2003; Yu et al., 2008). 
CLA isomers play a principal role in many important physiological functions and may lead to changes in body composition, body fat reduction, overall energy expenditure or modulate immune function and inhibit tumorigenesis (Banni et al., 2004; King et al., 2004; Rainer and Heiss, 2004). Considering the above evidence, we investigated whether a diet enriched in Se-Y stimulated the accumulation of conjugated linoleic acid (CLA) isomers in rat livers and femoral muscles.

The objective of our studies was to determine the effects of Se-Y and CLA isomer mixture (CLAmix) on the profile of CLA isomers and other FA concentrations in the liver and femoral muscles of rats. Furthermore, the influence of the experimental diets on the concentrations of selected amino acids, $\mathrm{Zn}, \mathrm{Fe}$ and Se in the liver and muscles was studied.

\section{MATERIAL AND METHODS}

\section{Animals, diets and sampling}

The investigation was carried out on 32 female rats (Wistar, Ifz: BOA), 8 weeks of age and with an initial body weight of $200 \pm 1 \mathrm{~g}$. The rats were housed individually in plastic cages at a temperature of $22 \pm 1^{\circ} \mathrm{C}$ with a $12 \mathrm{~h}$ light-dark cycle and relative humidity of 50-60\%. Each group comprised 7 or 8 rats. During a one-week preliminary period the rats were fed a standard Labofeed $\mathrm{H}$ diet (Table 1) according to the recommendations of Pastuszewska et al. (2000). This diet was offered at a sub-maintenance level (i.e. $8 \mathrm{~g}$ diet per rat and day) to reduce the body fat content in rats. Consequently, the body weight of animals decreased by about $15 \mathrm{~g}$ per rat during the preliminary period lasting 7 days. Finally, the animals were fed experimental diets supplemented with a CLA isomer mixture and/or Se (as high-selenized yeast; Sel-Plex, Alltech Inc., USA) ad libitum (Table 1). The dietary CLA isomer mixture contained: trans, transCLA isomers (ttCLA), 1.94\%; cis9, trans11CLA (c9t11CLA) and trans10,cis12CLA (t10c12CLA), 95.57\%; cis, cisCLA isomers (ccCLA), 1.48\%; and linoleic acid (LA) 1.0\%. The ratio (R) of the $c 9 t 11$ CLA to $110 c 12$ CLA concentration in the CLA isomer mixture in the rats' diets was 0.981 (i.e. 47.3 and $48.2 \%$, respectively). Feed intake and body weight were measured weekly. At the end of the 28-day experiment the animals were killed. Liver and femoral muscles were removed, weighed and frozen. Amino acids (AA), fatty acids (FA) as well as Se, $\mathrm{Zn}$ and Fe were analysed in liver and femoral muscles. 
Table 1. Chemical composition ( $\mathrm{g} / 100 \mathrm{~g}$ diet) and the energy value of the Labofeed $\mathrm{H}$ diet (Pastuszewska et al., 2000) and Se-Y (high selenized yeast, Sel-Plex) (Rayman, 2004) and dietary CLA isomer mixture ${ }^{1}$

\begin{tabular}{lclc}
\hline Item & Labofeed $\mathrm{H}^{3} \mathrm{~g} / 100 \mathrm{~g}$ diet & \multicolumn{1}{c}{ Item } & $\mathrm{Se}-\mathrm{Y}$ \\
\hline Dry matter $^{2}$ & $88.2 \pm 0.9$ & $\mathrm{Se}$ & $\begin{array}{c}1.8 \mathrm{mg} \mathrm{Se} / \mathrm{g} \\
\text { yeast }\end{array}$ \\
$\begin{array}{lll}\text { In dry matter } \\
\quad\end{array}$ & & \\
$\quad$ crude protein & $21.8 \pm 1.3$ & sum of identified Se species & $88.3 \% \mathrm{Se}$ \\
lysine & 1.31 & Se-methionine & $83.0 \% \mathrm{Se}$ \\
methionine+cystine & 0.76 & Se-cysteine & $5.0 \% \mathrm{Se}$ \\
tryptophan & 0.28 & selenite & $0.3 \% \mathrm{Se}$ \\
threonine & 0.87 & fatty acids ${ }^{4}$ & $\mathrm{mg} / \mathrm{g}$ yeast \\
crude fibre & $21.8 \pm 1.3$ & C16:0 & 9.0 \\
fat & $3.0 \pm 0.8$ & Cis9C16:1 & 4.1 \\
ash & $5.9 \pm 0.6$ & C18:0 & 13.6 \\
Energy value, MJ, ME/kg & 13.9, mean from 3 samples & Cis9C18:1 & 11.3 \\
& & Cis $11 \mathrm{C} 18: 1$ & 0.8 \\
& & Cis9cis $12 \mathrm{C} 18: 2$ (LA) & 14.7 \\
& & Cis9cis 12 cis $15 \mathrm{C} 18: 3$ (LNA) & 0.16 \\
\hline
\end{tabular}

${ }^{1}$ the CLA isomer mixture contained: $1.94 \% t, t$ CLA isomers, $95.57 \% c 9 t 11 \mathrm{CLA}$ and $t 10 c 12 \mathrm{CLA}$, and $1.48 \% c, c$ CLA isomers and $1 \%$ linoleic acid (LA); the ratio of the $c 9 t 11$ CLA to $t 10 c 12 \mathrm{CLA}$ contents in the CLA isomer mixture was 0.981 (i.e. 47.3 and $48.2 \%$, respectively). The composition of individual isomers: $c 9 t 11$ CLA and $t 10 c 12$ CLA: $98 \%$ of $c 9 t 11$ CLA and $t 10 c 12$ CLA, respectively; $t, t$ CLA isomers: $0.2 \%$; LA: $1 \%$

${ }^{2}$ ingredients: maize, wheat, oat flakes, green meal, soyabean oilmeal, fishmeal, soya oil, vitamins; macro-elements (Na, K, Ca and P: 3.6, 8.3, 10.7 and $7.6 \mathrm{mg} / \mathrm{g}$ Labofeed $\mathrm{H}$ diet, respectively) and trace elements ( $\mathrm{Se}$ as $\mathrm{Na}_{2} \mathrm{SeO}_{3}, \mathrm{Cu}, \mathrm{Zn}, \mathrm{Mn}, \mathrm{Fe}, \mathrm{Mg}$ : 0.63, 13.9, 98, 112, 698, $1653 \mu \mathrm{g} / \mathrm{g}$ Labofeed $\mathrm{H}$ diet, respectively)

${ }^{3}$ means from 9 samples

${ }^{4}$ main FA peaks (i.e. $\sim 95 \%$ area of all FA peak areas in a GLC chromatogram

\section{Reagents and analytical methods}

Organic solvents were of HPLC grade and all chemicals were analytical grade. Dichloromethane (DCM), $\mathrm{KOH}, \mathrm{NaOH}, \mathrm{Na}_{2} \mathrm{SO}_{4}$ and conc. $\mathrm{HCl}$ were purchased from $\mathrm{POCH}$ (Gliwice, Poland). Methanol, acetonitrile (ACN) and n-heptane (99.5\%, HPLC) were supplied by Lab-Scan (Ireland), while the CLA isomer mixture by Larodan Fine Chemicals AB (Sweden). Composition details and the purity of CLA isomer(s) were examined using our $\mathrm{Ag}^{+}$-HPLC and GLC methods (Table 1) according to Czauderna et al. (2003a, 2005a). Fatty acid methyl ester standards, methionine (Met), cysteine (Cys) and $25 \% \mathrm{BF}_{3}$ in methanol were purchased from Supelco or Sigma (USA). The high-selenized yeast (SeSaccharomyces cerevisiae) was donated by Sel-Plex (non-commercial yeast sample; Alltech In., USA). About $83 \%$ of the total Se content of high-selenized 
yeast (Se-Y) represents $\mathrm{Se}$ in the form of Se-methionine incorporated into the proteins of Saccharomyces cerevisiae (Table 1). Water used for the preparation of chemical reagents and mobile phases was prepared using an Elix ${ }^{\mathrm{TM}}$ water purification system (Millipore). The mobile phases were filtered through a 0.45 $\mu \mathrm{m}$ membrane filter (Millipore).

\section{Saponification and preparation of fatty acid methyl esters (FAME)}

Liver and muscles were frozen, lyophilized, finely powdered and the obtained samples were stored at $-20^{\circ} \mathrm{C}$ until analysis. The underivatized CLA isomers and other fatty acids (FA) containing conjugated double bonds (CFA) were determined using silver-ion exchange liquid chromatography ( $\left.\mathrm{Ag}^{+}-\mathrm{HPLC}\right)$ according to Czauderna et al. (2003). All fatty acids (FA), including CLA isomers and CFA, in liver and muscles were saponified (Czauderna et al., 2007a) followed by gentle base- and acid-catalysed methylations (Czauderna et al., 2008). Finally, methylated fatty acids (FAME) were quantified using capillary gas-chromatography with mass spectrometry (GC-MS) according to Czauderna et al. (2008). Amino acid (AA) concentrations in all assayed biological samples were determined via o-phthaldialdehyde-derivatives according to Czauderna et al. (2002).

The concentrations of Se (via $\mathrm{Se}^{82}$ ) in liver and muscles were analysed by the fluorimetric method of Rodriguez et al. (1994), while the level of Fe and $\mathrm{Zn}$ in these samples was determined by flame atomic absorption spectrometry (Czauderna et al., 2005b).

\section{Analytical equipment}

The analyses of all FAME were performed on a SHIMADZU GC-MS-QP2010 Plus EI equipped with a BPX70 fused silica capillary column $(120 \mathrm{~m} \times 0.25 \mathrm{~mm}$ i.d. $\times 0.25 \mu \mathrm{m}$ film thickness; SHIM-POL). The underivatized CLA isomers and other fatty acids containing conjugated double bonds (CFA) were analysed on an $\mathrm{Ag}^{+}$-HPLC (Waters, USA). This system comprised two ion-exchange columns loaded with silver ions $(250 \times 4.6 \mathrm{~mm}$ i.d., Chrompack ChromSper $5 \mu \mathrm{m}$, Lipids, The Netherlands) and a Waters 996 photodiode array detector (Czauderna et al., 2005a). Concentrations of $\mathrm{Fe}, \mathrm{Cu}$ and $\mathrm{Zn}$ in biological samples were determined on a PU9100X Atomic Absorption Spectrometer, UNICAM, Philips.

\section{Statistical analyses}

Results are presented as means \pm SD of individually analysed samples of liver and muscles. Statistical analyses of the effects of dietary Se and CLA isomer mixture were conducted using the non-parametric Mann-Whitney $U$ test for 
comparing independent experimental groups. Differences were considered significant at ${ }^{\mathrm{a}, \mathrm{b}} \mathrm{P}<0.05$ or ${ }^{\mathrm{A}, \mathrm{B}} \mathrm{P}<0.01$, while at ${ }^{\alpha, \beta} \mathrm{P}<0.1$ differences were taken as tendencies. Statistical analyses of the interaction between CLA isomer mixture and Se were performed using two factorial ANOVA analysis. For statistical analyses the program Statistica ver. 6 (2002; www.statsoft.pl) was used.

\section{RESULTS AND DISCUSSION}

The influence of dietary CLA isomers and Se on liver, muscles and body weight of rats and the concentration of elements and amino acids in liver and muscles. In the current study, no macroscopic lesions or pathological changes were found in the liver and femoral muscles or in any of other organs of rats fed the diets enriched in the CLAmix and/or Se-Y. Indeed, diets containing up to $2 \mathrm{mg}$ Se per $\mathrm{kg}$ would not be toxic for rodents (McDowell et al., 2005). Only chronic consumption of inorganic Se compounds, selenate and especially selenite, at rates of more than $5 \mathrm{mg}$ Se per $\mathrm{kg}$ diet can be hepatotoxic and teratogenic in humans and animals (Tapiero et al., 2003; Tinggi, 2003). The $\mathrm{LD}_{50}$ is $\sim 5 \mathrm{mg}$ Se per $\mathrm{kg}$ body weight for rats, which corresponds to about 50 $\mathrm{mg}$ Se per kg diet. Fortunately, in contrast to selenide and selenite, Se-Met is less reactive, and because $t$ RNAMet does not discriminate between Se-Met and methionine, dietary Se-Met is incorporated into body protein in place of methionine (Tapiero et al., 2003; Weiss and Hogan, 2005). Consequently, Se-Met as a Se-Met residue in general proteins is a stable and safe-storage mode for Se in the body of animals and humans.

There were no differences $(\mathrm{P}>0.05)$ in the final body weight $(\mathrm{BW})$ among the groups of rats fed the diets enriched in the CLAmix or/and Se-Y compared with the appropriate control groups (Table 2). However, BW was numerically lower $(-1.6 \%)$ in the CLA group compared with the control group, while the Se-CLA diet most efficiently elevated BW $(+3.5 \%$ and $+1.8 \%)$ in the Se-CLA group compared with the CLA and the control groups, respectively. Moreover, dietary Se-Y and CLAmix most effectively increased the mass of the liver and the liver concentration sum of FA ( $\Sigma F A)$, as well as the Se concentration in the liver and muscles compared with all other groups. The diet containing only CLAmix caused an increase in the value of the ratio of $\mathrm{Fe} / \mathrm{Zn}$ concentrations in both tissues compared with all other groups of rats. This finding confirms the opinion that dietary CLA isomers (especially $t 10 c 12 \mathrm{CLA}$ ) enhanced the pro-oxidative activity of species present in rats. On the other hand, dietary Se-Y resulted in a decrease in the value of the ratio of $\mathrm{Fe} / \mathrm{Zn}$ concentrations, supporting the mediatory effect of Se-Y (especially Se-methionine) on reducing the pro-oxidative capacity of species present in the body of animals. 


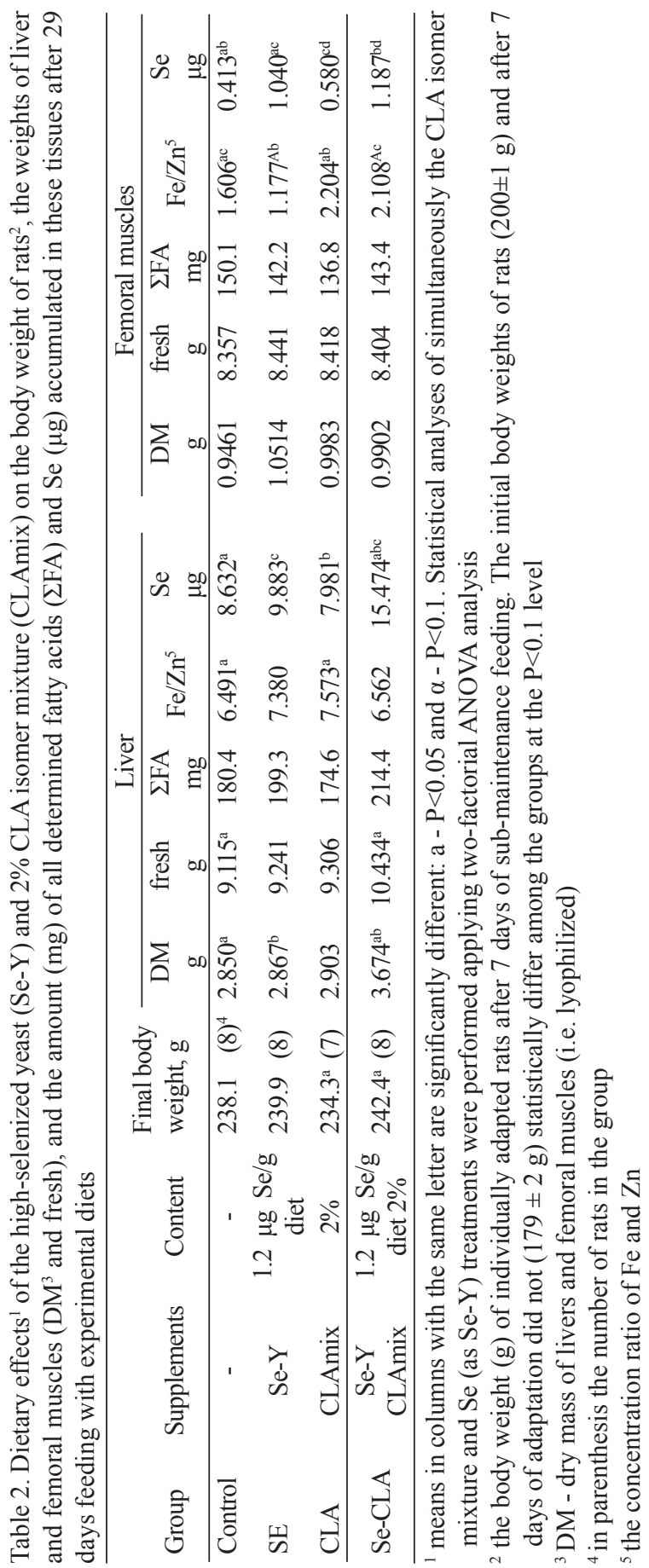


The Se-CLA diet most efficiently increased the concentration of essential $(+46 \%)$, non-essential $(+39 \%)$ and sulphur amino acids $(+138 \%)$ in muscles compared with the control diet as well as the CLA diet $(+31 \%$, $+67 \%$ and $+66 \%$, respectively) and the SE diet $(+72,+40$ and $+91 \%$, respectively). The Se-CLA diet also most efficiently increased the concentration of taurine in the liver and muscles compared with all other groups, whereas the concentration of taurine was substantially lower in the liver and muscles of rats fed the diet enriched in Se-Y compared with rats fed other diets. Thus, the results from the current study confirm that dietary Se-methionine (i.e. the main Se-component of Se-Y) results in a decrease in the conversion yield of methionine (via taurine) to cysteine (Czauderna et al., 2007b), whereas the interaction between Se-Y and CLAmix stimulated the accumulation of methionine as well as the conversion yield of methionine to cysteine in muscles (Czauderna et al., 2007b).

The current trial has demonstrated that the muscle concentration of essential amino acids, sulphur amino acids in particular, can be significantly increased, while the muscle content of FA, decreased by feeding the Se-CLA diet. Therefore, this finding of our short-term pilot study constitutes valuable information for nutritionists carrying out studies to improve the performance of domestic animals via dietary Se-Y and CLA isomer mixture.

The influence of dietary CLA isomers and Se on the concentration of selected fatty acids in liver and muscles. Dietary Se-Y or CLAmix lead to a statistically insignificant decrease in the concentrations of atherogenic (A-SFA) and thrombogenic (T-SFA) saturated fatty acids in muscles, concomitantly these changes have a negligible influence on the values of the atherogenic (A-SFA index) and thrombogenic (T-SFA index) indexes (Table 3). Surprisingly, the Se-CLA diet resulted in an increase in the values of A-SFA and T-SFA indexes in the liver and muscles, while there were negligible changes in the concentrations of A-SFA and T-SFA in muscles and only a small increase of the T-SFA concentration in the liver.

The diet enriched in only CLAmix most effectively increased the concentration

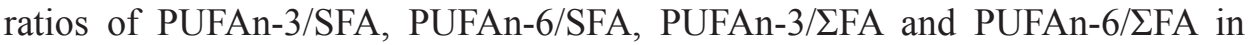
muscles. On the other hand, the Se-CLA diet resulted in a decrease in the values of these ratios in the liver. The concentrations of CLA isomers in muscles were ten-fold higher $(\mathrm{P}<0.01)$ than in the liver, regardless of the presence of extra Se in diets. Thus, the results of our pilot study of the concentrations of $\Sigma \mathrm{S}-\mathrm{AA}, \Sigma \mathrm{E}-$ AA, A-SFA, T-SFA, CLA isomers and the above values of fatty acid ratios in muscles of the CLA group rats is a valuable finding for nutritionists carrying out investigations to improve the performance of domestic monogastric animals via a dietary mixture of cis 9 trans 11CLA and trans10cis 12 CLA $(1: 1, \mathrm{w} / \mathrm{w})$.

The yield of the metabolism of trans10cis12CLA was higher in both tissues than of cis9trans11CLA. Moreover, our results show that trans10cis12CLA was 


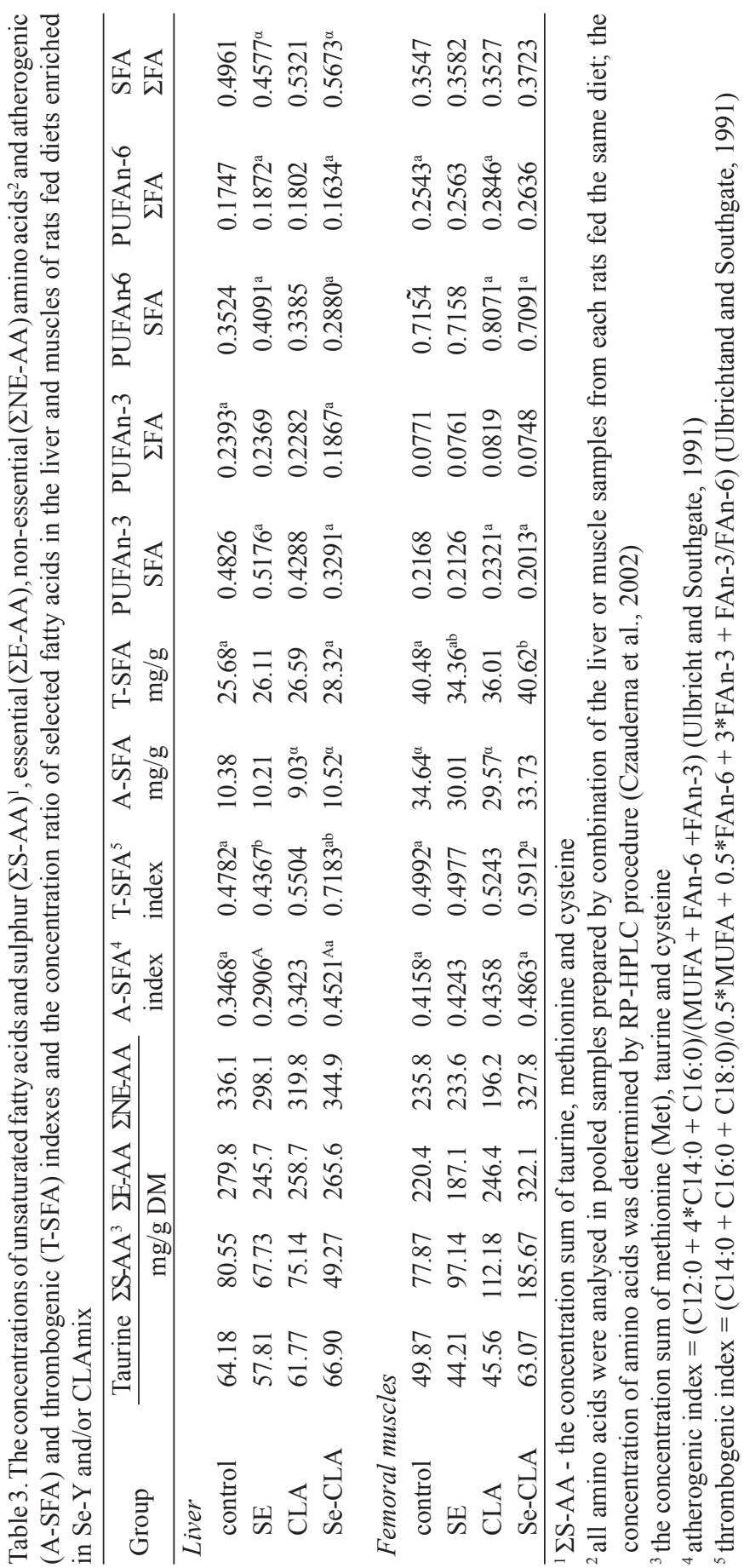


preferentially metabolized in the liver compared with the metabolic efficiency of this isomer in muscles (Table 4). The addition of Se-Y to the diet enriched in CLAmix resulted in further elevation of the metabolic yield of trans10cis12CLA in the liver, while slightly decreased that in muscles. Based on the concentration of $\alpha$-linolenic acid ( $\alpha$ LNA) in both tissues (see the elongase and $\Delta 5$-desaturase index in Table 4 ) we suggest that the diet enriched in CLAmix, regardless of the presence of Se-Y, decreased the elongation and $\Delta 5$-desaturase capacities in the liver and muscles. Similarly, the diet containing CLAmix, regardless of the presence of Se-Y, reduced the concentration of cis9MUFA in both tissues (Table 4). This is consistent with the reduction of the capacity of $\Delta 9$-desaturation in the liver, muscles and other organs of rats or rabbits (Czauderna et al., 2007a,b; Korniluk et al., 2007). Moreover, the results of feeding diets enriched in CLAmix with or without Se-Y demonstrate that these diets also decreased the capacity of $\Delta 4$-desaturation in muscles. Considering the above it seems reasonable to suggest that CLA isomers, especially trans 10cis 12, stimulated oxidation processes in mammals (Basu et al., 2000). Moreover in concert, dietary CLA isomers decreased the capacity of dehydrogenation processes like $\Delta 4$ or $\Delta 9$-desaturation in muscles, in particular. Moreover, CLA isomers may compete with certain fatty acids (i.e. substrates) at the level of desaturases and elongases, therefore influencing the formation yield of more unsaturated and longer chain fatty acids. Moreover, CLA isomers decreased the expression of the gene for stearoylCoA reductase, which is the initial $\Delta 9$-desaturation. The results reported here reinforce the finding of our previous studies with respect to a possible role for CLA isomers in influencing desaturation of selected fatty acids in kidneys, spleen and pancreas in rats (Korniluk at al., 2007). Recent studies also documented that these isomers reduced the capacity of other desaturases, i.e. $\Delta 6$-desaturase (Malcolm et al., 2008). Indeed, supplementation of CLAmix decreased the $\Delta 6$-desaturase capacity in the liver compared with the control rats (Table 4). Moreover, the current study demonstrated that the addition of Se-Y to the diet enriched in CLAmix amplified a decrease of $\Delta 6$-desaturase capacity in the liver and muscles compared with rats fed the control diet or the diet with CLAmix.

The use of Se-Y as an additive to the rats' diet led to significantly lower ratios of $\Sigma$ S-AA, Met, Cys and taurine to Se concentrations in the liver and muscles of rats than in the control group (Table 4). Thus, our current investigation confirmed the Se-species antagonism towards sulphur-compounds in living organisms (Suzuki, 2005; Surai, 2006). Indeed, the main Se-component of Se-Y, Se-Met, can be incorporated into protein non-specifically in place of Met; excess incorporation of Se-Met into proteins can influence protein function if Se-Met replaces Met at the active site of an enzyme (Schrauzer, 2000). The extent of the incorporation of dietary Se-Met into protein depends upon the Met status of the animal: when Met is limiting, incorporation of Se-Met is increased. Moreover, when Met, cysteine or Se-cysteine are deficient, Se-Met conversion via Se-taurine into Se-cysteine and 


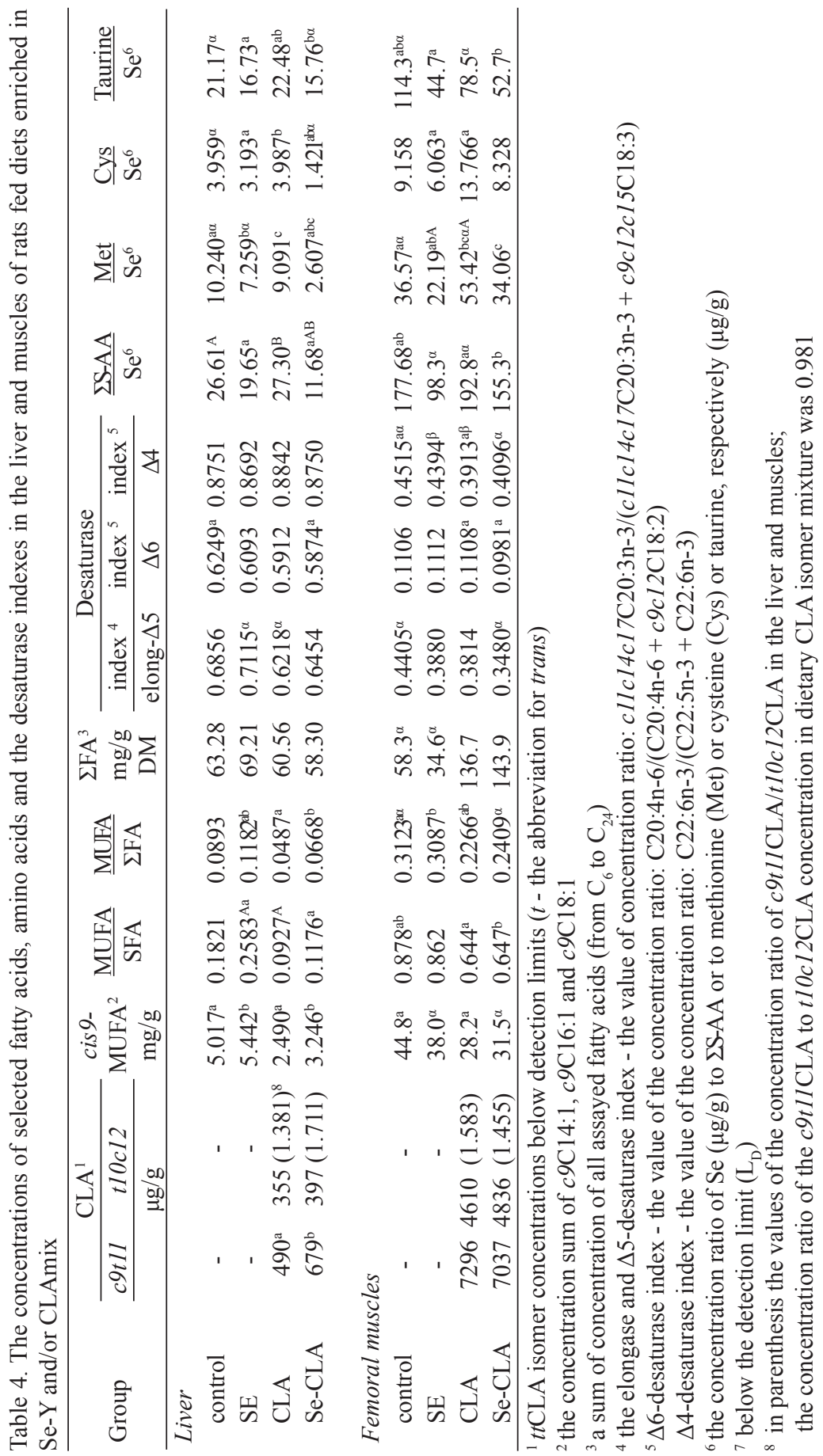


then incorporation (instead of cysteine) at the active site of GSHPx or other Seenzymes is higher because of non-specific incorporation of Se-Met than selenite or selenate into body stores. Moreover, the addition of CLAmix to the diet enriched in Se-Y resulted in further decrease of these ratios in the liver compared with control rats, while slightly increasing them in muscles compared with the SE group of rats. Therefore, we suggest that CLA isomers, as well as their metabolites, amplified the antagonistic effect of Se-Met towards Met, cysteine and taurine, especially in the liver. On other hand, there was no noticeable interaction between and CLAmix (Se-Y $\times$ CLAmix) because the metabolic capacity of dietary CLA isomers and SeMet was smaller in femoral muscles compared with the liver.

\section{CONCLUSIONS}

Dietary supplementation of a CLA isomer mixture, regardless the presence of extra selenized yeast, seems to be an efficient way of increasing the concentration of cis9trans11CLA and trans10cis12CLA in the liver and especially in femoral muscles of rats, as well as in other monogastric animals like rabbits, nutrias or pigs (King et al., 2004). The interaction between Se-Y and CLAmix results in a major increase in the Se concentration in the liver and especially in muscles; this increase is concomitant with increasing in the concentration of sulphur-, essential, and non-essential AA in muscles, thus protein synthesis and, consequently, rat body weight. The results reported here documented that the interaction between Se-Y and CLAmix resulted in decreased desaturation capacity in the liver and muscles, therefore, these dietary additives reduced the ratio of unsaturated to saturated fatty acid concentrations (i.e. (MUFA+PUFA)/SFA) in the liver and muscles.

\section{REFERENCES}

Banni S., Petroni A., Blasevich M., Carta G., Angioni E., Murru E., Day B.W., Melis M.P., Spad S., Clement C., 2004. Detection of conjugated C16 PUFAs in rat tissues as possible partial betaoxidation products of naturally occurring conjugated linoleic acid and its metabolites. Biochim. Biophys. Acta 1682, 120-127

Boosalis M.G., 2008. The role of selenium in chronic disease. Nutr. Clin. Pract. 23, 152-160

Basu S., Smedman A., Vessby B., 2000. Conjugated linoleic acids induced lipid peroxidation in humans. FEBS Lett. 468, 33-36

Crespo A.M., Reis M.A., Lanca M.J., 1995. Effect of selenium supplementation on polyunsaturated fatty acids in rats. Biol. Tr. Elem. Res. 47, 335-341

Czauderna M., Kowalczyk J., Bulska E., Boldižarova K., Niedźwiedzka K.M., Ruszczyńska A., Leng L'., 2005b. Effect of dietary CLA isomers on selenium, zinc, copper, chromium, magnesium and calcium levels in rat liver. J Anim. Feed Sci. 14, Suppl. 1, 529-532 
Czauderna M., Kowalczyk J., Korniluk K., Niedźwiedzka K.M., 2007b. Comparison of the influence of different chemical forms of selenium and the profiles of CLA isomers in the diet on the fatty acid and amino acid contents in the liver and femoral muscles of rats. J. Anim. Feed Sci. 16, 678-695

Czauderna M., Kowalczyk J., Korniluk K., Wąsowska I., 2005a. Improving the analysis of fatty acids using a combination of gas chromatography and $\mathrm{Ag}^{+}$liquid chromatography. J. Anim. Feed Sci. 14, Suppl. 1, 563-566

Czauderna M., Kowalczyk J., Korniluk K., Wąsowska I., 2007a. Improved saponification base and acid-catalyzed methylation is a useful method for quantifying fatty acids, with special emphasis on conjugated dienes. Acta Chromatogr. 18, 59-71

Czauderna M., Kowalczyk J., Niedźwiedzka K.M., Korniluk K., Kaszuba A., 2008. Determination of conjugated linoleic acid isomers using capillary gas chromatography and mass spectrometry. Proceedings of the XXIII International Symposium on the Physico-Chemical Methods of Separation. Nicolaus Copernicus University in Torun (Poland) “Ars Separatoria 2008”, pp. 93 96

Czauderna M., Kowalczyk J., Niedźwiedzka K.M., Wąsowska I., 2002. Determination of free- and protein primary amino acids in biological materials by high-performance liquid chromatography and photodiode array detection. J. Anim. Feed Sci. 11, 143-167

Czauderna M., Kowalczyk J., Wąsowska I., Niedźwiedzka K.M., 2003. Determination of conjugated linoleic acid isomers by liquid chromatography and photodiode array detection. J. Anim. Feed Sci. 12, 269-282

King D.A., Behrends J.M., Jenschke B.E., Rhoades R.D., Smith S.B., 2004. Positional distribution of fatty acids in triacylglycerols from subcutaneous adipose tissue of pigs fed diets enriched with conjugated linoleic acid, corn oil, or beef tallow. Meat Sci. 67, 675-681

Korniluk K., Czauderna M., Kowalczyk J., 2007. The influence of dietary conjugated linoleic acid isomers and high-selenized yeast on the fatty acid profile of spleen, pancreas and kidneys of rats. J. Anim. Feed Sci. 16, 121-139

McDowell L.R., Davis P.A., Cristaldi L.A., Wilkinson N.S., Buergelt C.D., Van Alstyne R., 2005. Toxicity of selenium: fear or precaution? Feedstuffs 77 (22), 12-13

Ogborn R.M., Nitschmann E., Goldberg A., Calic N.B., Weiler H.A., Aukema H.M., 2008. Dietary conjugated linoleic acid renal benefits and possible toxicity vary with isomer, dose and gender in rat polycystic kidney disease. Lipids 43, 783-791

Pastuszewska B., Ochtabińska A., Morawski A., 2000. A note on the nutritional adequacy of stock diets for laboratory rats and mice. J. Anim. Feed Sci. 9, 533-542

Rainer L., Heiss C., 2004. Conjugated linoleic acid: health implications and effects on body composition. J. Amer. Diet. Assn. 104, 963-968

Rayman P.M., 2004. Review article. The use of high-selenium yeast to raise selenium status: how does it measure up? Brit. J. Nutr. 92, 557-573

Raymond F.B., Kristina E.H., 2005. Selenoprotein P: An extracellular protein with unique physical characteristics and a role in selenium homeostasis. Annu. Rev. Nutr. 25, 11.1-11.21

Rodriguez E.M., Sanz M.T., Romero C.D., 1994. Critical study of fluorometric determination of selenium in urine. Talanta 41, 2025-2031

Schomburg L., Schweizer U., Köhrle J., 2004. Selenium and selenoproteins in mammals: extraordinary, essential, enigmatic. Cell. Mol. Life Sci. 61, 1988-1995

Schweizer U., Streckfub F., Pelt P., Carlson B.A., Hatfield D.L., Köhrle J., Schomburg L., 2005. Hepatically derived selenoprotein $\mathrm{P}$ is a key factor to kidney but not for brain selenium supply. Biochem. J. 386, 221-226

Surai P.F., 2006. Selenium in Nutrition and Health. Nottingham University Press, Nottingham (UK) 
Suzuki K.T., 2005. Metabolomics of selenium: Se metabolites based on speciation studies. J. Health Sci. 51, 107-114

Tanguy S., Besse S., Ducros V., Leiris J., Boucher F., 2003. Effect of increased dietary selenium intake on blood and cardiac selenium status during aging in rats. Nutr. Res. 23, 239-243

Tapiero H., Townsend D.M., Tew K.D., 2003. The antioxidant role of selenium and selenocompounds. Biomed. Pharmacotherapy 57, 134-144

Ulbricht T.L.V., Southgate D.A.T., 1991. Coronary heart disease: seven dietary factors. Lancet 338, 985-992

Weiss W.P., Hogan J.S., 2005. Effect of selenium source on selenium status, neutrophil function, and response to intramammary endotoxin challenge of dairy cows. J. Dairy Sci. 88, 4366-4374

Whanger P.D., 2004. Selenium and its relationship to cancer: an update. Brit. J. Nutr. 91, 11-28

Yu L.L., Wang R.L., Zhang Y.Z., Kleemann D.O., Zhu X.P., Jia Z.H., 2008. Effects of selenium supplementation on polyunsaturated fatty acid concentrations and anti-oxidant status in plasma and liver of lambs fed linseed oil or sunflower oil diets. Anim. Feed Sci. Tech. 140, 39-51 